\title{
Fine-Needle Biopsy: Should This Be the First Choice in Endoscopic Ultrasound-Guided Tissue Acquisition?
}

\author{
Eun Young Kim \\ Department of Internal Medicine, Catholic University of Daegu School of Medicine, Daegu, Korea
}

\begin{abstract}
Endoscopic ultrasound (EUS)-guided tissue acquisition is an indispensable technique for the diagnosis of many diseases of the gastrointestinal tract and adjacent structures. EUS-guided fine-needle aspiration (EUS-FNA) is known for its high accuracy and low complication rate. However, the outcome of EUS-FNA highly depends on several factors such as the location and characteristics of the lesion, endosonographer's experience, technique of sampling and sample preparation, type and size of the needle used, and presence of a cytopathologist for rapid on-site examination. EUS-guided fine-needle biopsy is useful to obtain core tissue samples with relatively fewer passes. Aspiration of core tissue with preserved architecture is beneficial for the diagnosis of certain diseases and the performance of ancillary testing such as tumor molecular profiling. Issues related to needle size, type, and their acquired samples for cytologic and histologic evaluation are discussed here.
\end{abstract}

Key Words: Endoscopic ultrasound-guided tissue acquisition; Endoscopic ultrasound-guided fine-needle aspiration; Endoscopic ultrasound-guided fine-needle biopsy; Cytology; Core biopsy

\section{INTRODUCTION}

Endoscopic ultrasound (EUS)-guided tissue acquisition is the diagnostic procedure of choice in many diseases of the gastrointestinal tract and adjacent structures. This procedure is well known for its high accuracy and low complication rate; however, its outcome closely relies on several factors. The location and characteristics of the lesion, endosonographer's experience, needle size and type, sampling technique, sample preparation, presence of a cytopathologist for rapid on-site examination (ROSE), and cytologist's expertise are considered some of the important factors. ${ }^{1,2}$ Issues related to needle selection will be discussed here.
Received: June 10, 2014 Accepted: July 26, 2014

Correspondence: Eun Young Kim

Department of Internal Medicine, Catholic University of Daegu School of Medicine, 33 Duryugongwon-ro 17-gil, Nam-gu, Daegu 705-718, Korea

Tel: +82-53-650-4092, Fax: +82-53-624-3281, E-mail: kimey@cu.ac.kr

(C) This is an Open Access article distributed under the terms of the Creative Commons Attribution Non-Commercial License (http://creativecommons.org/ licenses/by-nc/3.0) which permits unrestricted non-commercial use, distribution, and reproduction in any medium, provided the original work is properly cited.

\section{NEEDLES FOR EUS-GUIDED TISSUE ACQUISITION}

\section{EUS-guided fine-needle aspiration}

Currently, there are three different sizes of commercially available EUS fine-needle aspiration (EUS-FNA) needles: 19, 22 , and 25 gauge $(G)$. The size of the needle should be chosen consciously because it can directly affect the quality of the procured sample. Generally speaking, a 22 G EUS-FNA needle is most commonly used. A $25 \mathrm{G}$ needle is better for the transduodenal approach. Larger needles may render bigger tissue for diagnosis; however, samples tend to be bloodier, which might hinder the cytologic interpretation. As a $19 \mathrm{G}$ conventional needle is stiff and has limitation in the transduodenal approach, a new flexible $19 \mathrm{G}$ nitinol needle (Expect 19G Flex; Boston Scientific, Natick, MA, USA) has been introduced. ${ }^{3}$ Recently, a new side-port needle has been developed by Olympus (Tokyo, Japan), and it is expected to allow better cellular acquisition. ${ }^{4}$

\section{EUS-guided fine-needle biopsy}

The spring-loaded $19 \mathrm{G}$ biopsy needle TruCut (Cook Medical, Winston-Salem, NC, USA) has been designed for the pro- 
curement of tissue core samples; ${ }^{5}$ however, it is not feasible to use with the transduodenal approach and has been reported to result in technical failures. The newly developed ProCore needle (Cook Medical), which incorporates reverse bevel technology, has various available sizes and enables the transduodenal approach. ${ }^{6}$

\section{OUTCOME OF EUS-GUIDED TISSUE ACQUISITION}

The advantage of EUS-guided tissue acquisition is its high accuracy and safety. According to a meta-analysis, the pooled diagnostic sensitivity and specificity of EUS-FNA in the diagnosis of solid pancreatic masses were $86.8 \%$ (95\% confidence interval [CI], 85.5 to 87.9 ) and $95.8 \%$ (95\% CI, 94.6 to 96.7 ), respectively. ${ }^{7}$ However, there is no consensus on the number of passes to achieve the highest diagnostic accuracy. Increased number of passes may yield a higher diagnostic accuracy with a theoretically higher complication rate. The average numbers of passes to obtain an adequate diagnostic sample for a solid lesion are known to be five to seven passes for the conventional FNA needle. However, the mean number of passes required for diagnosis with the new Olympus $22 \mathrm{G}$ side-port needle was only 1.7 in a prospective multicenter study; however, the number of enrolled cases in that study was small. ${ }^{8}$ The ProCore needle seems to be able to obtain enough tissue for diagnosis with only a few passes. When single and multiple (two to four) passes of the $25 \mathrm{G}$ ProCore needle were compared in the diagnosis of solid pancreatic lesions, the sensitivity, specificity, and accuracy were $85 \%$ vs. $96 \%, 100 \%$ vs. $100 \%$, and $86 \%$ vs. $96 \%$, respectively. ${ }^{9}$ In a prospective study, the diagnostic accuracy of EUS-guided TruCut needle core biopsy was $61 \%$, with a mean value of 1.4 needle passes. ${ }^{10}$ The transduodenal approach was possible only in $40 \%$ of the patients. When subgroup analysis was done on technically successful cases only, the diagnostic accuracy was $87.5 \%$. In a multicenter, pooled, cohort study, the overall diagnostic accuracy of the 19 G ProCore needle was $85 \% .{ }^{6}$ During transduodenal procedures, sampling was done in $94 \%$; however, there were some technical difficulties. The combination of EUSFNA/fine-needle biopsy (FNB) techniques revealed the highest diagnostic accuracy of $91 \%$ compared with $77 \%$ for EUSFNA alone and $73 \%$ for EUS-FNB alone $(p=0.008) .{ }^{11}$ Another study showed an $84 \%$ diagnostic accuracy with EUS-guided TruCut needle biopsy and suggested the additional use of EUS-FNA as a rescue diagnostic tool. ${ }^{12}$

EUS-FNB is useful in obtaining core tissue with a few passes. ROSE is critical for the high diagnostic accuracy of EUSFNA; ${ }^{13}$ however, if an endosonographer can obtain visible tissue core with an FNB needle, the outcome may not be de- pendent on ROSE, which is not always readily available for many institutions. Aspiration of core tissue with preserved architecture is beneficial for the diagnosis of some specific diseases such as submucosal masses, ${ }^{14}$ lymphomas, ${ }^{15}$ and autoimmune pancreatitis. ${ }^{16}$ As molecular profiling and personalized oncologic therapy are becoming important concepts nowadays, a histologic core biopsy sample is necessary for ancillary testing. ${ }^{17}$ Tissue core can be obtained with a conventional aspiration needle or a specialized FNB needle. A study reported that satisfactory histologic specimens were procured in $94.7 \%$ and tissue acquisition for cytological assessment was successful in $100 \%$, including the transduodenal route, when an Expect 19 G Flex aspiration needle was used. ${ }^{3}$ The high tissue acquisition rate is partially because of the high elasticity of the needle, which facilitates the transduodenal pass.

Complications related to EUS-FNA include bleeding, acute pancreatitis, and infection. The complication rate of EUSFNA is about $2 \%$ to $3 \%$. Small pancreatic lesions $(<2 \mathrm{~cm})$ and nueroendocrine tumors are related to a higher complication rate; however, no definite relation was proven with patient's age, location of lesion, needle size, and number of needle passes. ${ }^{18}$ The type of needle does not seem to pose a big difference in the complication rate.

\section{PERFORMANCE COMPARISON OF VARIOUS NEEDLES}

Many studies reported that there was no significant difference in diagnostic outcome and needle size. A study reported that the diagnostic accuracy of the $19 \mathrm{G}$ needle for solid pancreatic and peripancreatic masses was $86.7 \%$ and that of the $22 \mathrm{G}$ needle was $78.9 \%(p=0.268) .{ }^{19}$ A $19 \mathrm{G}$ aspiration needle could render a higher amount of tissue; however, technical failure was more frequent when the mass was located in the head of the pancreas. When technical failures were excluded, the diagnostic accuracy of the $19 \mathrm{G}$ needle was $94.5 \%$. The $25 \mathrm{G}$ needle allows better maneuverability because it is sharp and more flexible. It can be easily bent in a perpendicular direction and also has a wider puncture range. That is why it can afford better target accessibility and a precise puncture. Therefore, the $25 \mathrm{G}$ needle is better for targeting pancreatic head and uncinate lesions through the transduodenal route. The obtained sample size may be smaller, but it might result in minimal blood contamination. In a prospective, randomized trial comparing 22 and $25 \mathrm{G}$ needles for solid pancreatic masses, the tissue samples provided positive diagnosis in $87.5 \%$ in the $22 \mathrm{G}$ group and $95.5 \%$ in the $25 \mathrm{G}$ group $(p=0.18) .{ }^{20}$ According to a meta-analysis, the pooled sensitivity of the 22 and 25 G needles was 0.85 (95\% CI, 0.82 to 0.88 ) and 0.93 (95\% CI, 0.91 to 0.96 ), respectively. The pooled specificity of the 22 
and 25 G needle was 1 (95\% CI, 0.98 to 1.00) and 0.97 (95\% CI, 0.93 to 0.99 ), respectively. The $25 \mathrm{G}$ needle showed a higher sensitivity ( $p=0.0003$ ) but comparable specificity to ( $p=0.97)$ the $22 \mathrm{G}$ needle. ${ }^{21}$

Another study showed that the overall accuracy of the 25 and 22 G EUS-FNA needles and the $19 \mathrm{G}$ TruCut needle was $91.7 \%, 79.7 \%$, and $54.1 \%$, respectively, in the diagnosis of solid pancreatic masses. ${ }^{22}$ For head and uncinate lesions, the $25 \mathrm{G}$ FNA needle was technically more successful and had significantly superior overall diagnostic accuracy than the other needles. A study compared same-sized FNA and FNB needles for the diagnosis of solid pancreatic neoplasms and reported a striking result. ${ }^{23}$ When five passes of the $22 \mathrm{G}$ Echotip Ultra needle and two passes of the 22 G Echotip Procore needle were performed for same lesion alternately for 32 cases, the ability to achieve a diagnosis was $93.8 \%$ for FNA and $28.1 \%$ for FNB. During the FNB procedure, five cases of technical failure and eight cases of tissue processing failure were reported. When the echoendoscope was positioned within the duodenum, FNB could not be performed because of technical reasons. The authors did not explain the details of tissue processing failures but noted that the "Procore needle failed to obtain enough tissue to survive processing as a regular core biopsy for histology (tissue attrition during processing)." However, a previous randomized trial that compared a $22 \mathrm{G} \mathrm{FNA}$ needle (Expect; Boston Scientific) and a 22 G FNB needle (Echotip ProCore; Cook Endoscopy, Bloomington, IN, USA) for solid pancreatic masses reported different results. ${ }^{24}$ The diagnostic sufficiency was $100 \%$ and $89.3 \%(p=0.24)$ for the FNA and FNB needle, respectively. The $22 \mathrm{G}$ biopsy needle procured both cytologic and histologic specimen $(89.3 \%$ and $80 \%$, respectively), with a $3.6 \%$ technical failure rate. The complication rates were the same (3.6\% for both). According to a meta-analysis, needle size confers only a limited effect on the overall outcomes in EUS-FNA for solid pancreatic masses. ${ }^{25}$ A study compared 22 G EUS-FNA without ROSE and 19 G TruCut biopsy. ${ }^{26}$ The overall accuracy was $76 \%$ for both procedures, whereas the combination of the two procedures rendered a 95\% diagnostic accuracy. The median number of passes was 4.4 for FNA and 2.8 for TruCut biopsy. Thus, EUSFNB showed a similar diagnostic accuracy to EUS-FNA without ROSE, with fewer passes. The authors reported that they can obtain a positive report with EUS-FNB when EUS-FNA was negative in cases of gastrointestinal stromal tumors, pancreatic adenocarcinoma, lung cancer, metastatic mediastinal node, retroperitoneal lymphoma, and mediastinal lymphoma. ${ }^{26}$

\section{WHICH NEEDLE IS THE BEST CHOICE?}

Usually, a cytological sample is enough to establish a diag- nosis; however, histologic assessment may be useful in some cases such as pancreatic tumors other than pancreatic adenocarcinoma, tumors surrounded by chronic pancreatitis, submucosal and intramural gastrointestinal tumors, and for the biopsy of lesions or lymph nodes in which lymphoma is suspected. ${ }^{17}$ Certain diseases such as autoimmune pancreatitis, well-differentiated adenocarcinoma, and highly desmoplastic pancreatic neoplasm may also require tissue core samples for a definitive diagnosis. Histological samples can often be obtained with a standard FNA needle, and addition of cell block examination can provide good information that is comparable to an FNB sample. ${ }^{27}$ Therefore, EUS-FNB can be a recommendable supplementary technique when additional tissue and histologic section are necessary for an accurate diagnosis and if molecular characterization of tumors is required. ${ }^{8,17}$ The stiffness of the needle is a large obstacle to overcome in harvesting core tissues with the transduodenal approach. Certainly, cost-effectiveness is another factor to be considered. ${ }^{28}$

\section{CONCLUSIONS}

The needle size and type can be some of the factors that influence the diagnostic yield of EUS-guided tissue acquisition. There are no convincing data showing any significant advantage between the three commonly used FNA needle sizes. The smaller $25 \mathrm{G}$ needle, which yields at least comparable results to the 22 and $19 \mathrm{G}$ needles, may be easier to maneuver. Large-bore needles can procure more tissue; however, the sample tends to be bloodier and technical failure may occur. The yield of an FNB needle is higher with fewer passes and ancillary testing is usually possible. Needle selection is a complex process and should be made on the basis of many aspects, such as the location and physical characteristics of the lesion, availability of ROSE, and clinical needs considering the suspected diagnosis. $^{29}$

\section{Conflicts of Interest}

The author has no financial conflicts of interest.

\section{REFERENCES}

1. Kedia P, Gaidhane M, Kahaleh M. Technical advances in endoscopic ultrasound (EUS)-guided tissue acquisition for pancreatic cancers: how can we get the best results with EUS-guided fine-needle aspiration? Clin Endosc 2013;46:552-562.

2. Savides TJ. Tricks for improving EUS-FNA accuracy and maximizing cellular yield. Gastrointest Endosc 2009;69(2 Suppl):S130-S133.

3. Varadarajulu S, Bang JY, Hebert-Magee S. Assessment of the technical performance of the flexible 19-gauge EUS-FNA needle. Gastrointest Endosc 2012;76:336-343.

4. Kaffes A, Corte C. Fine-needle aspiration at endoscopic ultrasound with a novel side-port needle: a pilot experience. Therap Adv Gastroenterol 2012;5:89-94.

5. Jenssen C, Dietrich CF. Endoscopic ultrasound-guided fine-needle as- 
piration biopsy and trucut biopsy in gastroenterology: an overview. Best Pract Res Clin Gastroenterol 2009;23:743-759.

6. Iglesias-Garcia J, Poley JW, Larghi A, et al. Feasibility and yield of a new EUS histology needle: results from a multicenter, pooled, cohort study. Gastrointest Endosc 2011;73:1189-1196.

7. Puli SR, Bechtold ML, Buxbaum JL, Eloubeidi MA. How good is endoscopic ultrasound-guided fine-needle aspiration in diagnosing the correct etiology for a solid pancreatic mass?: a meta-analysis and systematic review. Pancreas 2013;42:20-26.

8. Kaffes AJ, Chen RY, Tam W, et al. A prospective multicenter evaluation of a new side-port endoscopic ultrasound-fine-needle aspiration in solid upper gastrointestinal lesions. Dig Endosc 2012;24:448-451.

9. Iwashita T, Nakai Y, Samarasena JB, et al. High single-pass diagnostic yield of a new 25-gauge core biopsy needle for EUS-guided FNA biopsy in solid pancreatic lesions. Gastrointest Endosc 2013;77:909-915.

10. Larghi A, Verna EC, Stavropoulos SN, Rotterdam H, Lightdale CJ, Stevens PD. EUS-guided trucut needle biopsies in patients with solid pancreatic masses: a prospective study. Gastrointest Endosc 2004;59:185190.

11. Wittmann J, Kocjan G, Sgouros SN, Deheragoda M, Pereira SP. Endoscopic ultrasound-guided tissue sampling by combined fine-needle aspiration and trucut needle biopsy: a prospective study. Cytopathology 2006;17:27-33.

12. Ginès A, Wiersema MJ, Clain JE, Pochron NL, Rajan E, Levy MJ. Prospective study of a Trucut needle for performing EUS-guided biopsy with EUS-guided FNA rescue. Gastrointest Endosc 2005;62:597-601.

13. Matynia AP, Schmidt RL, Barraza G, Layfield LJ, Siddiqui AA, Adler DG. Impact of rapid on-site evaluation on the adequacy of endoscopicultrasound guided fine-needle aspiration of solid pancreatic lesions: a systematic review and meta-analysis. J Gastroenterol Hepatol 2014;29: 697-705.

14. Kim GH, Cho YK, Kim EY, et al. Comparison of 22-gauge aspiration needle with 22-gauge biopsy needle in endoscopic ultrasonographyguided subepithelial tumor sampling. Scand J Gastroenterol 2014;49: 347-354.

15. Yasuda I, Goto N, Tsurumi H, et al. Endoscopic ultrasound-guided fine-needle aspiration biopsy for diagnosis of lymphoproliferative disorders: feasibility of immunohistological, flow cytometric, and cytogenetic assessments. Am J Gastroenterol 2012;107:397-404.

16. Iwashita T, Yasuda I, Doi S, et al. Use of samples from endoscopic ultrasound-guided 19-gauge fine-needle aspiration in diagnosis of autoimmune pancreatitis. Clin Gastroenterol Hepatol 2012;10:316-322.

17. de la Fuente SG, Arnoletti JP. Beyond cytology: why and when does the oncologist require core tissue? Gastrointest Endosc Clin N Am 2014;
24:9-17.

18. Karadsheh Z, Al-Haddad M. Endoscopic ultrasound guided fine-needle tissue acquisition: where we stand in 2013? World J Gastroenterol 2014; 20:2176-2185.

19. Song TJ, Kim JH, Lee SS, et al. The prospective randomized, controlled trial of endoscopic ultrasound-guided fine-needle aspiration using $22 \mathrm{G}$ and $19 \mathrm{G}$ aspiration needles for solid pancreatic or peripancreatic masses. Am J Gastroenterol 2010;105:1739-1745.

20. Siddiqui UD, Rossi F, Rosenthal LS, Padda MS, Murali-Dharan V, Aslanian HR. EUS-guided FNA of solid pancreatic masses: a prospective, randomized trial comparing 22-gauge and 25-gauge needles. Gastrointest Endosc 2009;70:1093-1097.

21. Madhoun MF, Wani SB, Rastogi A, et al. The diagnostic accuracy of 22-gauge and 25-gauge needles in endoscopic ultrasound-guided fineneedle aspiration of solid pancreatic lesions: a meta-analysis. Endoscopy 2013;45:86-92.

22. Sakamoto H, Kitano M, Komaki T, et al. Prospective comparative study of the EUS guided 25-gauge FNA needle with the 19-gauge Trucut needle and 22-gauge FNA needle in patients with solid pancreatic masses. J Gastroenterol Hepatol 2009;24:384-390.

23. Strand DS, Jeffus SK, Sauer BG, Wang AY, Stelow EB, Shami VM. EUS-guided 22-gauge fine-needle aspiration versus core biopsy needle in the evaluation of solid pancreatic neoplasms. Diagn Cytopathol 2014;42:751-758.

24. Bang JY, Hebert-Magee S, Trevino J, Ramesh J, Varadarajulu S. Randomized trial comparing the 22-gauge aspiration and 22-gauge biopsy needles for EUS-guided sampling of solid pancreatic mass lesions. Gastrointest Endosc 2012;76:321-327.

25. Affolter KE, Schmidt RL, Matynia AP, Adler DG, Factor RE. Needle size has only a limited effect on outcomes in EUS-guided fine-needle aspiration: a systematic review and meta-analysis. Dig Dis Sci 2013;58: 1026-1034.

26. Storch I, Jorda M, Thurer R, et al. Advantage of EUS Trucut biopsy combined with fine-needle aspiration without immediate on-site cytopathologic examination. Gastrointest Endosc 2006;64:505-511.

27. Noda Y, Fujita N, Kobayashi G, et al. Diagnostic efficacy of the cell block method in comparison with smear cytology of tissue samples obtained by endoscopic ultrasound-guided fine-needle aspiration. J Gastroenterol 2010;45:868-875.

28. Bang JY, Varadarajulu S. Procore and flexible 19 gauge needle can replace trucut biopsy needle? Clin Endosc 2013;46:503-505.

29. Varadarajulu S, Hawes RH. The changing paradigm in EUS-guided tissue acquisition. Gastrointest Endosc Clin N Am 2014;24:1-7. 